\title{
Enzyme-treated Ecklonia cava extract inhibits adipogenesis through the downregulation of C/EBP $\alpha$ in 3T3-L1 adipocytes
}

\author{
IN-HYE KIM ${ }^{1}$ and TAEK-JEONG NAM ${ }^{1,2}$ \\ ${ }^{1}$ Institute of Fisheries Science, Pukyong National University, Busan 619-911; \\ ${ }^{2}$ Department of Food and Life Science, Pukyong National University, Busan 608-737, Republic of Korea
}

Received September 19, 2016; Accepted January 12, 2017

DOI: $10.3892 /$ ijmm.2017.2869

\begin{abstract}
In this study, we examined the inhibitory effects of enzyme- treated Ecklonia cava (EEc) extract on the adipogenesis of 3T3-L1 adipocytes. The components of Ecklonia cava (E. cava) were first separated and purified using the digestive enzymes pectinase (Rapidase ${ }^{\circledR}$ X-Press L) and cellulase (Rohament ${ }^{\circledR} \mathrm{CL}$ ). We found that the EEc extract contained three distinct phlorotannins: eckol, dieckol and phlorofucofuroeckol-A. Among the phlorotannins, dieckol was the most abundant in the EEc extract at $16 \mathrm{mg} / \mathrm{g}$. Then we examined the inhibitory effects of EEc extract treatment on differentiation-related transcription factors and on adipogenesis-related gene expression in vitro using 3T3-L1 adipocytes. 3T3-L1 pre-adipocytes were used to determine the concentrations of the EEc extract and Garcinia cambogia (Gar) extract that did not result in cytotoxicity. Glucose utilization and triglyceride (TG) accumulation in the EEc-treated adipocytes were similarly inhibited by $50 \mu \mathrm{g} / \mathrm{ml} \mathrm{EEc} \mathrm{and} 200 \mu \mathrm{g} / \mathrm{ml} \mathrm{Gar}$, and these results were confirmed by Oil Red O staining. Protein expression of adipogenesis differentiation-related transcription factors following treatment with the EEc extract was also examined. Only the expression of CCAAT/enhancer-binding protein (C/EBP) $\alpha$ was decreased, while there was no effect on the expression of $\mathrm{C} / \mathrm{EBP} \beta, \mathrm{C} / \mathrm{EBP} \delta$, and peroxisome proliferator-activated receptor $\gamma(\operatorname{PPAR} \gamma)$. Treatment with the EEc extract decreased the expression levels of adipogenesis-related genes, in particular sterol regulatory element binding protein-1c (SREBP-1c), adipocyte fatty acid binding protein (A-FABP), fatty acid synthase (FAS) and adiponectin. These results suggest that EEc extract treatment has an inhibitory effect on adipogenesis, specifically by affecting the activation of the $\mathrm{C} / \mathrm{EBP} \alpha$ signaling pathway and the resulting adipogenesis-related gene expression.
\end{abstract}

Correspondence to: Professor Taek-Jeong Nam, Department of Food and Life Science, Pukyong National University, 45 Yongso-ro, Nam-gu, Busan 608-737, Republic of Korea

E-mail:namtj@pknu.ac.kr

Key words: Ecklonia cava, enzyme, adipogenesis, 3T3-L1 adipocytes

\section{Introduction}

Obesity is the most common metabolic disease worldwide and is a major public health issue, particularly in developed countries (1). Obesity occurs by a complex interaction between genetic and environmental factors $(2,3)$, and is characterized by excessive fat cell size (hypertrophic obesity) or cell number (hyperplasic obesity). It is often associated with a high-calorie diet, type 2 diabetes, high blood pressure, cardiovascular disease, and/or metabolic complications (4-9). In addition to the associated morbidity, many metabolic complications, including type 2 diabetes, insulin resistance, hyperlipidemia, hypertension, stroke, coronary heart disease and cancer, have been linked to obesity (10-12). These complications result in higher mortality rates in obese patients compared to lean patients.

Adipogenesis, the process of pre-adipocyte differentiation into adipocytes, is the result of excess energy intake and lack of activity. Adipogenesis contributes to the deposition of excess fat in adipocytes during differentiation from pre-adipocytes. Multiple processes regulate adipogenesis, including pre-adipocyte proliferation, differentiation, and fatty acid oxidation and synthesis, and these processes are controlled by a number of factors. Adipogenesis includes concerted transcriptional and cellular events, including growth arrest, re-entry into the cell cycle for mitotic clonal expansion, and the initiation of transcription during differentiation (13-15). A number of genes have been shown to be involved in the development of obesity, including peroxisome proliferator-activated receptor $\gamma(\mathrm{PPAR} \gamma)$, CCAAT/enhancer-binding protein (C/EBP) $\alpha, \mathrm{C} / \mathrm{EBP} \beta$ and $\mathrm{C} / \mathrm{EBP} \delta$ (16-19). The expression levels of adipocyte-related proteins such as sterol regulatory element binding protein-1c (SREBP-1c), adiponectin, fatty acid synthase (FAS), adipocyte fatty acid binding protein-4 (A-FABP4), glucose transporter (GLUT4), lipoprotein lipase (LPL) and stearoyl-CoA desaturase-1 (SCD-1) (20-24) are also induced.

A number of drugs have been developed for the treatment of obesity that target appetite regulation, fat absorption and fat oxidation $(25,26)$. A number of these drugs have been withdrawn from the market because of low efficacy and side effects, thus only a few drugs remain $(27,28)$. For example, the anti-obesity drugs orlistat $\left(\mathrm{Xenical}^{\circledR}\right)$ and sibutramine are commonly prescribed, although they are associated with 
significant side effects such as bladder pain, diarrhea, fever, loss of appetite, nasal congestion and difficulty in sleeping (orlistat), and headache, insomnia, increased appetite, asthenia, nausea and anorexia (sibutramine) (29-31). Thus, there is clearly a need to develop safer and more effective anti-obesity drugs.

Brown algae may represent a renewable natural material for use as novel therapeutic agents because they are rich in bioactive substances, including sulfated polysaccharides, proteins, dietary fibers and carotenoids (32-40). Ecklonia cava (E. cava) is an edible marine brown algal species that mainly inhabits coastal Japan and Korea (41). It has rarely been used for food but has been widely utilized in the aquaculture of abalone and seashells. Studies of E. cava have reported its antioxidant (42-46), anti-inflammatory (47-50), anticancer $(51,52)$, and antibacterial $(53,54)$ properties.

Recently, studies have examined the physiological activity of E. cava because of its polyphenol components, which include phlorotannins (55-61). E. cava polyphenols exhibit antioxidant $(55,56)$ and anticancer $(51,52,59-61)$ properties as well as contribute to hair growth $(57,58)$. Polyphenol extracts of E. cava have the potential to treat Alzheimer's disease (62) and the polyphenolic extract Seanol affects lipid and glucose metabolism (63).

Previous studies have investigated the anti-obesity properties of E. cava extracts using zebrafish, mice and cell cultures (64-70). In the present study, enzyme-treated Ecklonia cava (EEc) extract was prepared using the digestive enzymes pectinase (Rapidase ${ }^{\circledR}$ X-Press L) and cellulase (Rohament ${ }^{\circledR} \mathrm{CL}$ ) for separation and purification of the effective components in E. cava. We examined the inhibitory effects of the EEc extract on adipocyte differentiation and adipogenesis-related gene expression in vitro using 3T3-L1 adipocytes. Garcinia cambogia (Gar) extracts are used as natural supplements and are known to suppress appetite and lower body fat by blocking the lipid synthesis pathway (71-73). A Gar extract was used as a positive control.

\section{Materials and methods}

Preparation of enzyme-treated E. cava extract. E. cava was purchased in 2013 from Taekyug-nongsan (Jeju-do, Korea). E. cava chips of approximately $5 \mathrm{~cm}$ were prepared by cutting the leaves and removing the stem and roots of the algae. The extract was prepared by placing $30 \mathrm{~kg} E$. cava chips in 750 liters of distilled water with the added enzymes $(300 \mathrm{~g}$ pectinase, Rapidase X-Press L and $300 \mathrm{~g}$ cellulase, Rohament $\mathrm{CL}$ ). The suspension was stirred for $24 \mathrm{~h}$ at $50^{\circ} \mathrm{C}$, centrifuged at $3,000 \mathrm{x} \mathrm{g}$ at $4^{\circ} \mathrm{C}$ for $20 \mathrm{~min}$, vacuum filtered, and then three volumes of $60 \%$ ethanol were added. After $18 \mathrm{~h}$, the solution was filtered and concentrated using rotary evaporation to $6^{\circ} \mathrm{Bx}$. The concentrated solution was made into a powder using a spray dryer. The final extract weighed $3.56 \mathrm{~kg}$, representing a yield of 10.7\% (EEc; JY202-MM130126R). Garcinia cambogia powder extract was purchased from ES Ingredient Co., Ltd. (Gyeonggi-do, Korea).

Cell culture. 3T3-L1 mouse fibroblast cells (CL-173) were obtained from the American Type Culture Collection (ATCC) (Rockvile, MD, USA), and were cultured at $37^{\circ} \mathrm{C}$ with $5 \% \mathrm{CO}_{2}$ in Dulbecco's Modified Eagle's Medium (DMEM) supplemented with $10 \%$ newborn calf serum (NBCS; Gibco, Life Technologies Corp., Auckland, New Zealand) containing $50 \mu \mathrm{g} / \mathrm{ml}$ penicillin, $25 \mu \mathrm{g} / \mathrm{ml}$ amphotericin B and $50 \mu \mathrm{g} / \mathrm{ml}$ streptomycin. At $70 \%$ confluency, the cells were harvested by trypsinization and seeded in 6-well plates in pre-adipocyte expansion medium (DMEM supplemented with 10\% NBCS). When $100 \%$ confluency was reached, the cells were fed differentiation medium [DMEM supplemented with $10 \%$ fetal bovine serum (FBS) containing $0.25 \mu \mathrm{M}$ dexamethasone, $0.5 \mathrm{mM} 3$-isobutyl-1-methylxanthine (IBMX) and $10 \mu \mathrm{g} / \mathrm{ml}$ insulin] for $48 \mathrm{~h}$. The medium was then replaced with adipocyte maintenance medium (DMEM supplemented with $10 \mu \mathrm{g} / \mathrm{ml}$ insulin) and changed every $48 \mathrm{~h}$ for 8 days.

Cell viability assay. Cell viability was estimated using a Cyto X cell viability assay kit (LPS solution, Daejeon, Korea). Cells were seeded in 96-well plates at $2 \times 10^{4}$ cells/well in $100 \mu \mathrm{l}$ medium and allowed to attach for $24 \mathrm{~h}$. Attached cells were treated with $12.5,50$, or $200 \mu \mathrm{g} / \mathrm{ml}$ EEc extract or Gar extract in serum-free medium (SFM) for $24 \mathrm{~h}$. Cyto X solution was added to the cells and incubation was carried out for $1 \mathrm{~h}$, and the absorbance of each well was measured at $450 \mathrm{~nm}$ using a FilterMAX F5 microplate reader (Molecular Devices LLC, Sunnyvale, CA, USA).

Glucose utilization assay. Cells were seeded in 6-well plates and differentiation was induced. Following differentiation, the cells were treated with $12.5,50$ or $200 \mu \mathrm{g} / \mathrm{ml}$ EEc extract or Gar extract for $24 \mathrm{~h}$. Glucose utilization was performed with a glucose assay kit (ASAN glucose kit; Asan Pharm Co., Gyeonggi-do, Korea), as per the manufacturer's instructions. Briefly, glucose in the cell medium of each well was allowed to react with the glucose assay reagent for $5 \mathrm{~min}$; then the contents were transferred to a 96-well plate, and the absorbance was measured at $500 \mathrm{~nm}$ using a microplate reader (Gen 5; Epoch BioTek Instrument, Inc., Winooski, VT, USA).

Triglyceride (TG) accumulation assay. Following differentiation, the cells were washed with phosphate-buffered saline (PBS), harvested in ice-cold PBS, and sonicated for $1 \mathrm{~min}$. To measure TG content, TG assay reagent was added to the cell lysate according to the manufacturer's instructions (Cleantech TG-S; Asan Pharm Co.). Briefly, each cell lysate (30 $\mu \mathrm{l})$ was reacted with the TG assay reagent solution for $10 \mathrm{~min}$, transferred to a 96-well plate, and then the absorbance was measured at $550 \mathrm{~nm}$.

Oil Red $O$ staining. Following differentiation, the cells were washed twice with PBS and fixed with $10 \%$ formaldehyde for $1 \mathrm{~h}$ at room temperature. After washing with PBS, the cells were stained with Oil Red O working solution [0.5 g Oil Red O (Sigma-Aldrich, St. Louis, MO, USA) in 60\% isopropanol] for $1 \mathrm{~h}$. After the staining solution was removed, the lipid droplets were washed with water and dried. Stained oil droplets in 3T3-L1 cells were imaged with a light microscope (Eclipse TS100-F; Nikon, Tokyo, Japan). To quantify the Oil Red O uptake, cells in each well were extracted with $1 \mathrm{ml} 100 \%$ isopropanol for $10 \mathrm{~min}$, transferred to a 96 -well plate, and then the absorbance was measured at $540 \mathrm{~nm}$ using a microplate reader. 


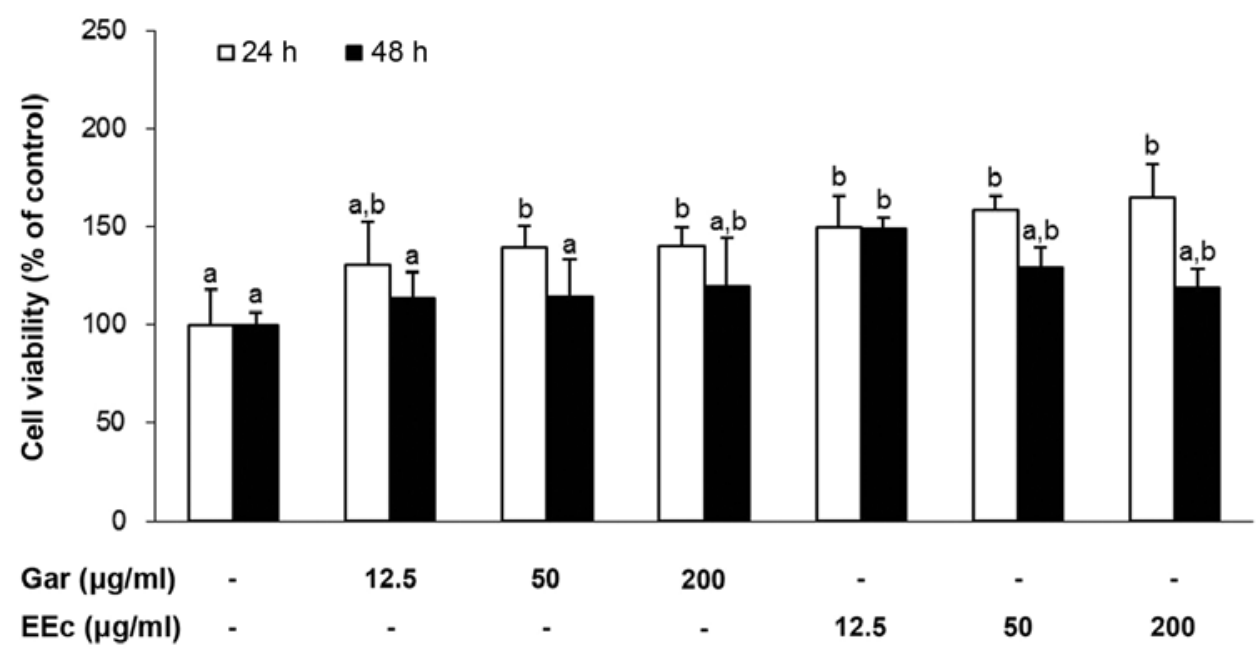

Figure 1. Treatment with Gar and EEc extracts does not cause cytoxicity in the 3T3-L1 pre-adipocytes. Effects of the treatment with the Gar and EEc extracts on cell viability were determined in 3T3-L1 pre-adipocytes by the Cyto X assay. Cells were treated with various concentrations of the Gar or EEc extracts. Data are presented as the means \pm standard deviation $(\mathrm{P}<0.05)$ from three independent experiments. Gar, Garcinia cambogia extract; EEc, enzyme-treated Ecklonia cava extract. The different letters at all concentrations represent significant differences $(\mathrm{P}<0.05)$ as determined by Duncan's multiple range test.

Western blot analysis. Following differentiation, the cells were incubated for $24 \mathrm{~h}$ in SFM containing 12.5, 50, or $200 \mu \mathrm{g} / \mathrm{ml}$ Gar or EEc extract. Then the cells were washed with PBS and lysed with extraction buffer $(20 \mathrm{mM}$ Tris, $150 \mathrm{mM} \mathrm{NaCl}$, $10 \%$ glycerol, $10 \mathrm{mM}$ sodium pyrophosphate, $100 \mu \mathrm{M}$ ammonium molybdate, $1 \mathrm{mM} \beta$-glycerophosphate, $0.1 \% \mathrm{NP}-40$, and $0.1 \%$ SDS, $\mathrm{pH} 8.0)$ containing protease inhibitors $(1 \mu \mathrm{g} / \mathrm{ml}$ aprotinin, $1 \mu \mathrm{g} / \mathrm{ml}$ leupeptin, $1 \mu \mathrm{g} / \mathrm{ml}$ pepstatin $\mathrm{A}, 100 \mu \mathrm{M}$ sodium orthovanadate and $1 \mathrm{mM}$ PMSF). The extracts were centrifuged at $9,750 \mathrm{x} \mathrm{g}$ for $10 \mathrm{~min}$, and the supernatant was used for western blot analysis.

Total protein $(40 \mu \mathrm{g})$ was electrophoresed on an SDS-PAGE gel and transferred to a polyvinylidene fluoride transfer membrane (Millipore Corp., Billerica, MA, USA). Membranes were blocked with $1 \%$ bovine serum albumin (BSA) in TBS-T (5 mM Tris- $\mathrm{HCl}, 20 \mathrm{mM}$ sodium chloride, $\mathrm{pH} 7.4$, and $0.1 \%$ Tween-20) and incubated with primary antibodies $(1: 1,000)$ in $1 \%$ BSA in TBS-T with gentle shaking overnight at $4^{\circ} \mathrm{C}$. Membranes were washed twice for $15 \mathrm{~min}$ in TBS-T, and incubated with the corresponding HRP-conjugated secondary antibodies $(1: 10,000)$ for $2 \mathrm{~h}$ at room temperature and washed again. The immunoreactive bands were detected using an enhanced chemiluminescence substrate (Advansta, Menlo Park, CA, USA) and visualized using the GeneSys imaging system (SynGene Synoptics, Ltd., London, UK). The following primary antibodies were used: anti-C/EBP $\alpha$ (sc-9314, anti-goat), anti-C/EBP $\beta$ (sc-150, anti-rabbit), anti-C/EBPS (sc-151, anti-rabbit), anti-PPAR $\gamma$ (sc-1984, anti-goat), anti-SREBP-1c (sc-366, anti-rabbit), anti-A-FABP (sc-18661, anti-goat), anti-FAS (sc-55580, anti-mouse), anti-GLUT4 (sc-1606, anti-rabbit), anti-adiponectin (sc-26497, anti-goat), anti-leptin (sc-842, anti-rabbit), and anti-glyceraldehyde-3-phosphate dehydrogenase (GAPDH) (sc-25778, anti-rabbit) (all from Santa Cruz Biotechnology, Inc., Santa Cruz, CA, USA). The secondary antibodies used were HRP-conjugated anti-mouse IgG (sc-2031, Santa Cruz Biotechnology, Inc.), anti-rabbit (A-0545, Sigma-Aldrich), and anti-goat (A50-101P, Bethyl Laboratories Inc., Montgomery, TX, USA).
Statistical analysis. The results are presented as mean \pm standard deviation of at least three independent experiments $(\mathrm{P}<0.05)$. Significant differences among multiple mean values were assessed by analysis of variance (ANOVA) followed by the Duncan's multiple range test using PASW statistics 18 (SPSS, Inc., Chicago, IL, USA). $\mathrm{P}<0.05$ was considered to indicate a statistically significant difference.

\section{Results}

EEc extract treatment does not exert cytotoxic effects on 3T3-L1 pre-adipocytes. To determine the effects of Gar or EEc extract treatment on the viability of the 3T3-L1 pre-adipocytes, the cells were treated with $12.5,50$ or $200 \mu \mathrm{g} / \mathrm{ml}$ Gar or EEc extract for 24 or 48 h. As shown in Fig. 1, treatment with Gar or EEc extract had no significant effect on the viability of the 3T3-L1 pre-adipocytes at $48 \mathrm{~h}$. However, treatment with $12.5,50$ or $200 \mu \mathrm{g} / \mathrm{ml}$ Gar extract significantly increased cell viability with values of $30.9,39$ and $39.9 \%$, respectively at $24 \mathrm{~h}$. Also, treatment with $12.5,50$, or $200 \mu \mathrm{g} / \mathrm{ml}$ EEc significantly increased cell viability at $49.8,58.3$ and $65.5 \%$, respectively at $24 \mathrm{~h}$, compared to the control group.

Therefore, we selected the maximum dose of Gar and EEc (200 $\mu \mathrm{g} / \mathrm{ml}$ ) for subsequent experiments to rule out the possibility that EEc-dependent inhibition of adipogenesis may be a result of its cytotoxic effects on 3T3-L1 cells. In subsequent experiments, cells were treated with $12.5,50$ or $200 \mu \mathrm{g} / \mathrm{ml} \mathrm{Gar}$ and EEc extract for $24 \mathrm{~h}$ without cytotoxicity.

EEc extract treatment inhibits glucose utilization and TG accumulation in the 3T3-L1 adipocytes. 3T3-L1 cells were induced to differentiate for 8 days and were then treated with various concentrations of EEc extract for $24 \mathrm{~h}$. As shown in Fig. 2A, glucose utilization was assessed following EEc extract treatment. In the positive control [receiving 3-isobutyl-1-methylxanthine, dexamethasone and insulin (MDI)], glucose utilization was $156 \pm 7.0 \mathrm{mg} / \mathrm{dl}$, while this was reduced to $84.4 \pm 17.9 \mathrm{mg} / \mathrm{dl}$ in the Gar group. Treatment with 
A

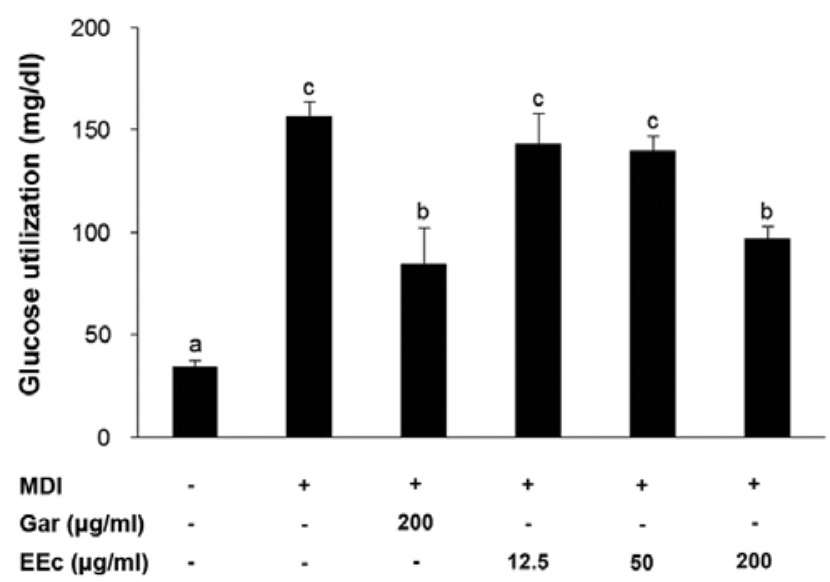

B

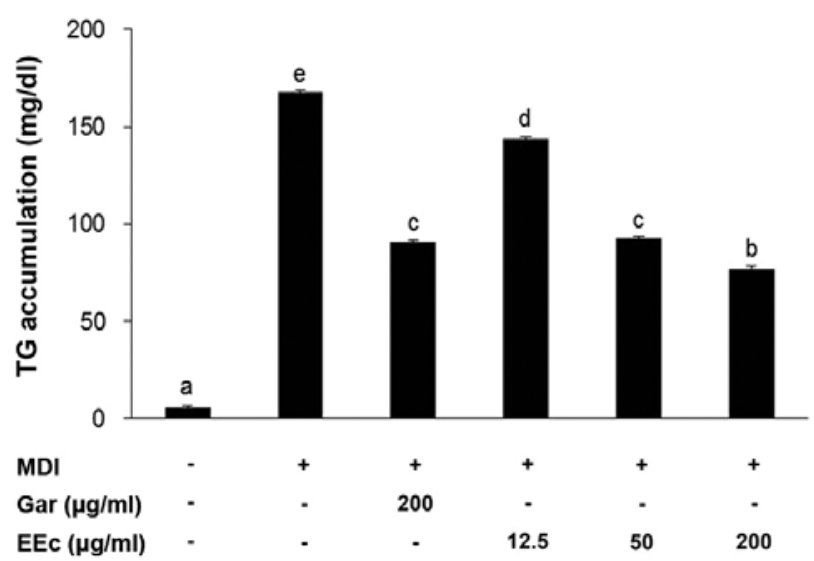

Figure 2. Treatment with the EEc extract inhibits glucose utilization and triglyceride accumulation in 3T3-L1 adipocytes. (A) 3T3-L1 adipocytes were incubated with or without various concentration of the Gar and EEc extracts for $24 \mathrm{~h}$. Glucose utilization in the culture medium was measured using glucose assay kit. (B) 3T3-L1 adipocytes were incubated with or without various concentration of the Gar and EEc extracts for $24 \mathrm{~h}$. TG accumulation in the cell lysate was measured using TG assay kit. Data are presented as the means \pm standard deviation $(\mathrm{P}<0.05)$ from three independent experiments. Gar, Garcinia cambogia extract; EEc, enzyme-treated Ecklonia cava extract; TG, triglyceride; MDI, 3-isobutyl-1-methylxanthine, dexamethasone, and insulin. The different letters at all concentrations represent significant differences $(\mathrm{P}<0.05)$ as determined by Duncan's multiple range test.

$12.5,50$, or $200 \mu \mathrm{g} / \mathrm{ml}$ EEc extract also reduced glucose utilization in a dose-dependent manner, with values of 143.5 \pm 14.6 , $139.8 \pm 7.3$ and $96.7 \pm 6.2 \mathrm{mg} / \mathrm{dl}$, respectively.

Next, we examined TG accumulation following EEc extract treatment of the 3T3-L1 adipocytes. We found that TG accumulation was $167.9 \pm 14.0 \mathrm{mg} / \mathrm{dl}$ in the MDI group while only $90.8 \pm 3.5 \mathrm{mg} / \mathrm{dl}$ in the Gar group (Fig. 2B). Treatment with $12.5,50$, or $200 \mu \mathrm{g} / \mathrm{ml} \mathrm{EEc} \mathrm{extract} \mathrm{resulted} \mathrm{in} \mathrm{significantly}$ reduced TG accumulation in a dose-dependent manner with values of $143.5 \pm 8.7,92.4 \pm 1.3$ and $77.1 \pm 1.3 \mathrm{mg} / \mathrm{dl}$, respectively. Consistent with these results, TG accumulation in the 3T3-L1 adipocytes treated with $200 \mu \mathrm{g} / \mathrm{ml} \mathrm{EEc} \mathrm{extract} \mathrm{was} \mathrm{lower} \mathrm{than}$ that in the Gar group.

EEc extract treatment increases adipogenesis in the 3T3-L1 adipocytes. Following the induction of differentiation, 3T3-L1 pre-adipocytes underwent morphological changes, including a transition from spindle-like features to a round shape and accumulation of intracellular lipids. Lipid accumulation is a known indicator of adipogenesis, and thus Oil Red O staining was used to examine whether EEc treatment influenced lipid accumulation in the adipocytes. As shown in Fig. 3A, EEc treatment decreased the intracellular lipid content compared to that noted in the MDI group as observed in images of the differentiated 3T3-L1 adipocytes.

The inhibitory effect of EEc extract treatment on lipid accumulation was confirmed by lipid droplet quantification (Fig 3B). Intracellular lipid content was markedly decreased to $53.7 \pm 2.7 \mu \mathrm{g} / \mathrm{ml}$ when the $3 \mathrm{~T} 3-\mathrm{L} 1$ adipocytes were treated with $200 \mu \mathrm{g} / \mathrm{ml}$ Gar extract (Fig. 3B). Treatment with 12.5, 50, or $200 \mu \mathrm{g} / \mathrm{ml}$ EEc extract reduced lipid content in the 3T3-L1 adipocytes by $52.2,53.2$ and $62.6 \%$, respectively, compared to these values in the MDI group.

EEc extract treatment decreases the protein levels of differentiation-related transcription factors. Adipogenesis is accompanied by a change in the sequential activation of several pro-adipogenic transcription factors, including $\mathrm{C} / \mathrm{EBP} \alpha / \beta / \delta$ and PPAR $\gamma$. Thus, we examined whether the reduced lipid accumulation in adipocytes was due to downregulation of these transcription factors. Compared to the differentiated control cells, EEc extract treatment significantly decreased the expression of $\mathrm{C} / \mathrm{EBP} \alpha$ but not $\mathrm{C} / \mathrm{EBP} \beta / \delta$ and PPAR $\gamma$ (Fig. 4). This suggests that EEc treatment inhibits adipogenesis by suppressing the expression of adipogenic transcription factors, particularly $\mathrm{C} / \mathrm{EBP} \alpha$.

EEc extract treatment reduces the expression of adipogenesis-related proteins. To examine the effects of EEc extract treatment on adipocytes, the expression of adipogenesis-related proteins was determined in the EEc-treated and untreated 3T3-L1 cells. We also determined the expression of other adipogenesis-related proteins involved in lipogenic and fatty acid oxidation and glucose homeostasis pathways. We found that EEc extract treatment inhibited the expression of adipogenic differentiation-related transcription factors in the 3T3-L1 cells. As shown in Fig. 5, differentiated cells exhibited significantly increased expression of PPAR $\gamma$ target genes in the adipogenesis pathway, including A-FABP, SREBP-1c, FAS and adiponectin. In contrast, EEc extract treatment significantly decreased the protein levels of SREBP-1c, A-FABP, FAS and adiponectin compared to levels noted in the differentiated control cells. No significant differences were apparent in regards to GLUT4 and leptin expression.

\section{Discussion}

Studies on E. cava have examined its antioxidant (42-46), anti-inflammatory $(47-50)$, anticancer $(51,52)$ and antibacterial $(53,54)$ properties. Recently, phlorotannins, the polyphenol component of E. cava, were examined with respect to their antioxidant $(55,56)$, anticancer $(51,52,59-61)$ and anti-obesity (64-70) properties, as well as their effects on hair growth $(57,58)$ and Alzheimer's disease (62). Inhibition 
A

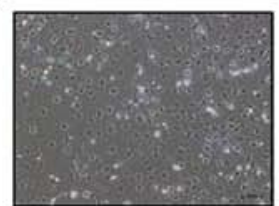

MDI

Gar $(\mu \mathrm{g} / \mathrm{ml})$.

$\mathrm{EEc}(\mu \mathrm{g} / \mathrm{ml})$ -

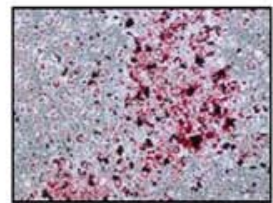

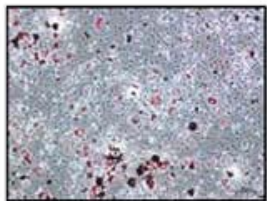

$+$

200

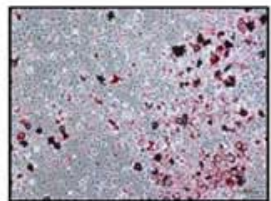

12.5

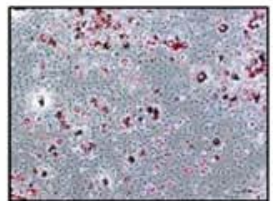

$+$

50

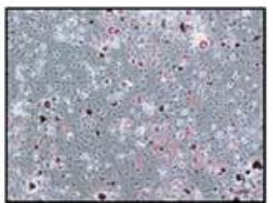

200

\section{B}

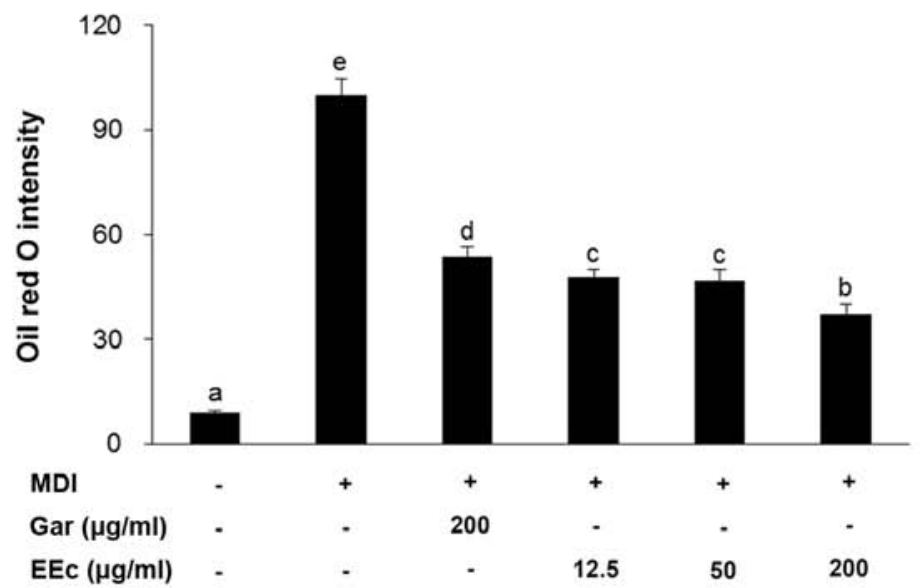

Figure 3. Treatment with the EEc extract inhibits lipid accumulation in the 3T3-L1 adipocytes. (A) 3T3-L1 pre-adipocytes were induced to differentiate in the absence or presence of the Gar and EEc extracts for $24 \mathrm{~h}$. The morphological changes associated with cell differentiation were imaged following Oil Red O staining. (B) Stained lipids were extracted and quantified by measuring the absorbance at $540 \mathrm{~nm}$. Data are presented as the means \pm standard deviation $(\mathrm{P}<0.05)$ from three independent experiments. Gar, Garcinia cambogia extract; EEc, enzyme-treated Ecklonia cava extract; MDI, 3-isobutyl-1-methylxanthine, dexamethasone, and insulin. The different letters at all concentrations represent significant differences $(\mathrm{P}<0.05)$ as determined by Duncan's multiple range test.

A

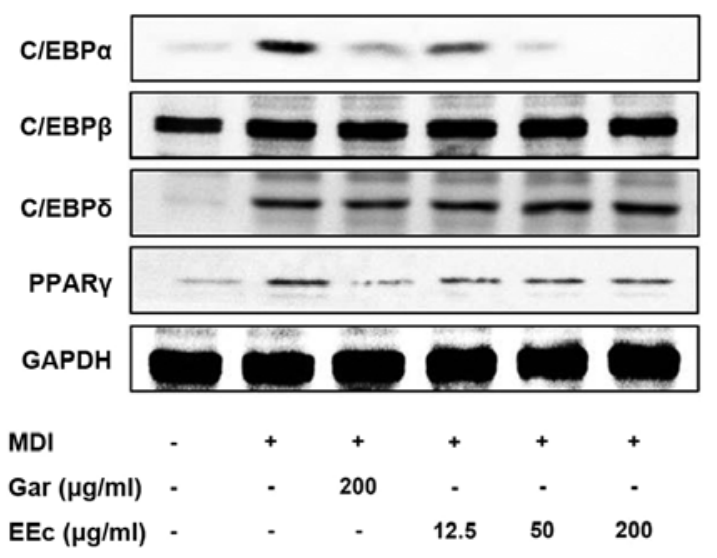

B
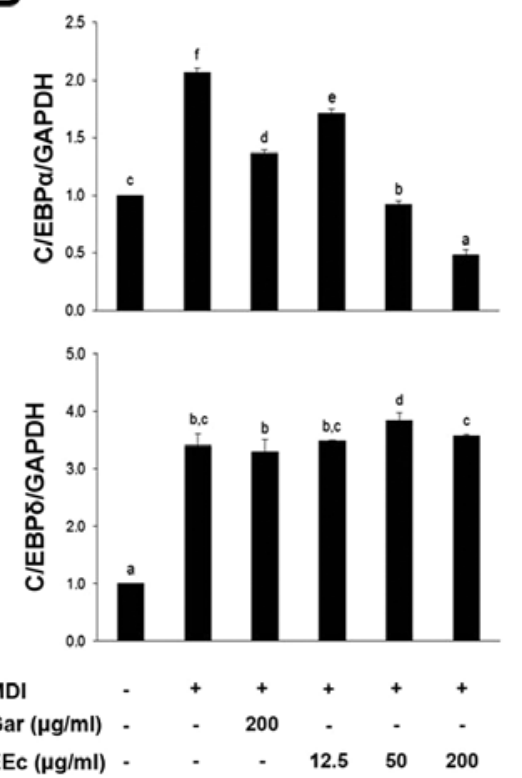
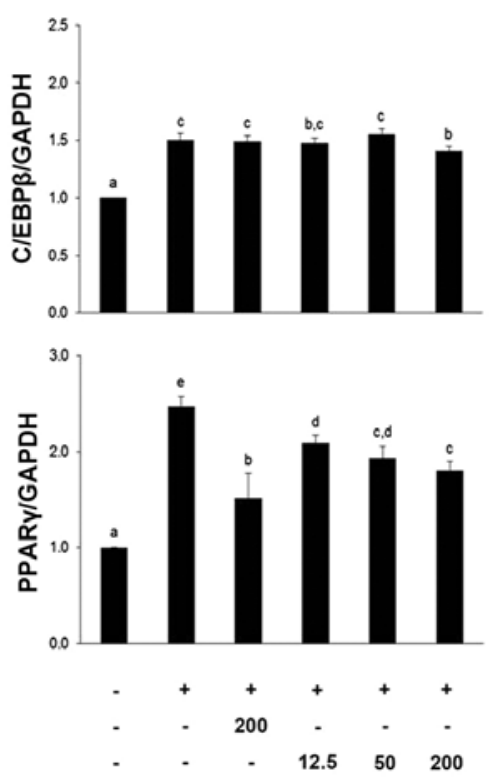

Figure 4. Treatment with the EEc extract inhibits the expression of differentiation-related transcription factors. (A) 3T3-L1 adipocytes were incubated with or without various concentrations of the EEc extract for $24 \mathrm{~h}$. Protein levels of PPAR $\gamma, \mathrm{C} / \mathrm{EBP} \alpha, \mathrm{C} / \mathrm{EBP} \beta$, and C/EBP $\delta$ were examined by western blotting as described in Materials and methods. (B) The bands were normalized to an internal control (GAPDH), and the relative ratio is graphed. Data are presented as the means \pm standard deviation $(\mathrm{P}<0.05)$ from three independent experiments. C/EBP, CCAAT/enhancer-binding protein; PPAR $\gamma$, peroxisome proliferator-activated receptor $\gamma$; Gar, Garcinia cambogia extract; EEc, enzyme-treated Ecklonia cava extract; MDI, 3-isobutyl-1-methylxanthine, dexamethasone, and insulin. The different letters at all concentrations represent significant differences $(\mathrm{P}<0.05)$ as determined by Duncan's multiple range test. 
A

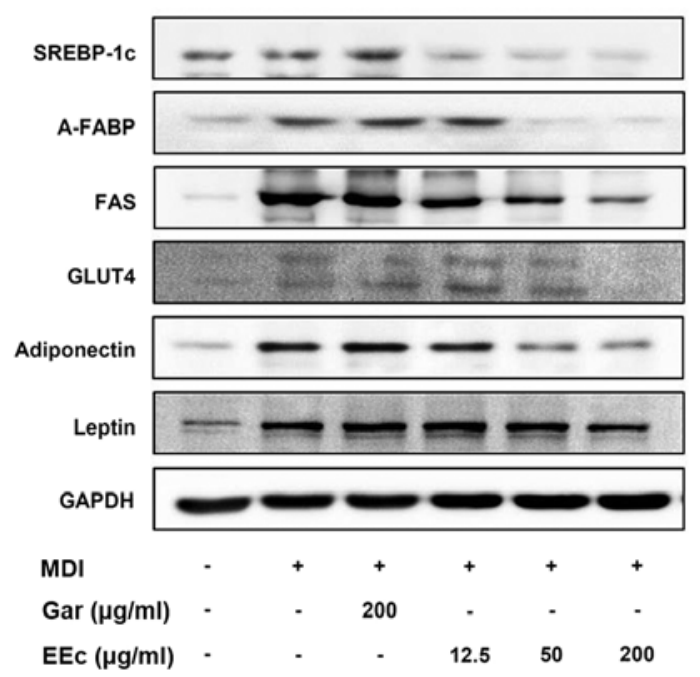

B
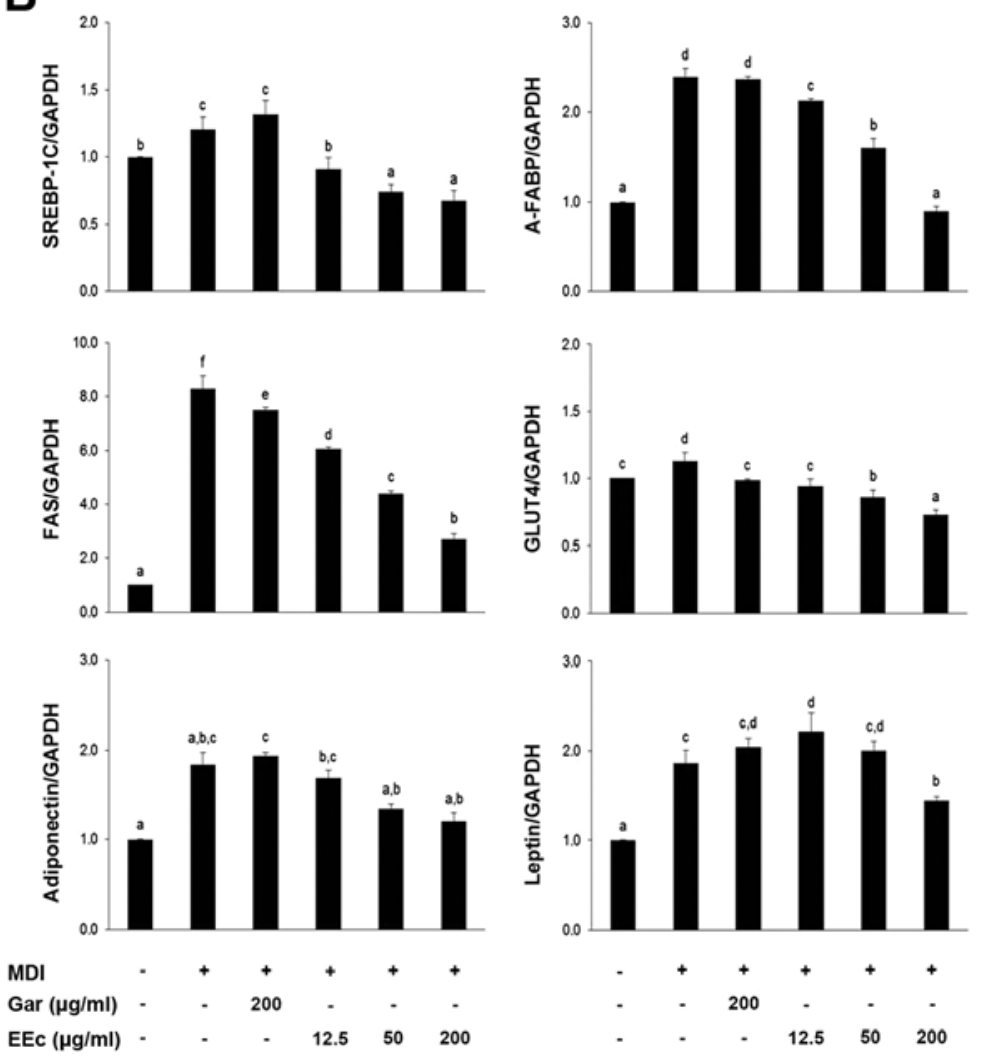

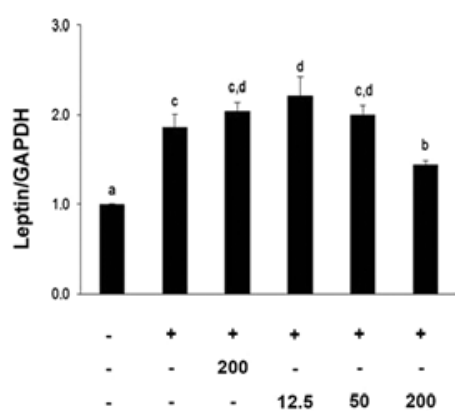

Figure 5. Treatment with the EEc extract inhibits expression of adipogenesis-related proteins. (A) 3T3-L1 adipocytes were incubated with or without various concentrations of the EEc extract for $24 \mathrm{~h}$. Protein levels of SREBP-1c, A-FABP, FAS, GLUT4, adiponectin and leptin were examined by western blotting as described in Materials and methods. (B) The bands were normalized to an internal control (GAPDH), and the relative ratio is graphed. Data are presented as the means \pm standard deviation $(\mathrm{P}<0.05)$ from three independent experiments. Gar, Garcinia cambogia extract; EEc, enzyme-treated Ecklonia cava extract; MDI, 3-isobutyl-1-methylxanthine, dexamethasone, and insulin; SREBP-1c, sterol regulatory element binding protein-1c; A-FABP, adipocyte fatty acid binding protein; FAS, fatty acid synthase. The different letters at all concentrations represent significant differences $(\mathrm{P}<0.05)$ as determined by Duncan's multiple range test.

of 3T3-L1 cell differentiation by E. cava extracts has been previously studied $(69,70)$. The diethyl ether fraction (69), methanolic extract and its solvent-partitioned fraction (70) of E. cava extract were examined for their antiadipogenic effect on 3T3-L1 adipocytes. Dieckol from the diethyl ether fraction was found to inhibit adipogenesis (69), and eckstolonol from the $\mathrm{n}-\mathrm{BuOH}$ fraction inhibited lipid accumulation (70).

In the present study, an E. cava extract was prepared using an enzyme-treatment high-yield extraction method with a high concentration of polyphenols, and then the effects of this extract on adipogenesis were determined.

We tested various methods to determine the optimal conditions for extraction of the extract of E. cava. We evaluated the following extraction methods: hot water treatment $\left(60^{\circ} \mathrm{C}\right.$, $\left.90^{\circ} \mathrm{C}\right)$, ethanol treatment $(60 \%, 80 \%)$, and enzymatic treatment (Protex $^{\mathrm{TM}}$ 6L, an endo-type protease; Rapidase ${ }^{\circledR}$ X-Press L, a pectinase-cellulase-hemicellulase enzyme complex; Rohament ${ }^{\circledR} \mathrm{CL}$, a cellulase- $\beta$-glucanase-hemicellulase enzyme complex). The resulting yields were as follows: hot water extraction, 19.31-27.75\%; ethanol extraction, 3.24-11.42\%; and enzyme extraction, $19.08-21.87 \%$. Specifically, the enzyme extraction yields were $21.06 \%$ with Protex 6L, 19.08\% with Rapidase X-Press L, $18.66 \%$ with Rohament CL, and $21.87 \%$ with the Rapidase X-Press L-Rohament CL complex. Hot water extraction resulted in a higher yield compared to enzyme extraction; however, we decided that enzyme extrac- tion was the ideal method. The total polyphenol content was also measured for each extraction method and ranged from 206.74 to $812.17 \mu \mathrm{g} / \mathrm{ml}$, with the $60 \%$ ethanol extraction having the highest content. We decided that this method had low economic efficiency as raw materials of $E$. cava were obtained at a lower yield. Therefore, enzyme extraction using the Rapidase X-Press L-Rohament CL complex was selected based on a consideration of both the total yield and cost effectiveness. High-performance liquid chromatographic analysis of the EEc extract revealed three components (eckol, dieckol, and phlorofucofuroeckol-A), and dieckol was the most abundant at $16 \mathrm{mg} / \mathrm{g}$. The hexamer of phloroglucinol and dieckol exhibits various biological properties, including antioxidant and anti-allergenic activity, and plays a role in immunomodulation (74-76).

We considered two directions when planning the present experiment. In other words, we considered whether to treat the sample during or after completion of differentiation. In many studies, it was known that sample treatment after the completion of differentiation inhibited the adipogenesis-related protein expression levels (64-70). Thus, we examined the inhibitory effects of the EEc extact treatment upon completion of adipocyte differentiation and adipogenesis in vitro in the 3T3-L1 adipocytes. First, we determined that treatment of 3T3-L1 pre-adipocytes with $12.5,50$, or $200 \mu \mathrm{g} / \mathrm{ml} \mathrm{Gar}$ or EEc extract did not result in cytotoxicity (Fig. 1). Glucose utiliza- 
tion and TG accumulation were confirmed following EEc extract treatment in the 3T3-L1 adipocytes. Both the Gar and EEc extract-treated groups showed similar glucose utilization at $200 \mu \mathrm{g} / \mathrm{ml}(96.7 \pm 6.2 \mathrm{mg} / \mathrm{dl}$ vs. $84.4 \pm 17.9 \mathrm{mg} / \mathrm{dl})$, as well as similar TG accumulation at $50 \mu \mathrm{g} / \mathrm{ml}(92.4 \pm 1.3 \mathrm{mg} / \mathrm{dl}$ vs. $90.8 \pm 3.5 \mathrm{mg} / \mathrm{dl}$ ) (Fig. 2). Overall, we found that EEc extract treatment decreased glucose utilization and TG accumulation in the 3T3-L1 adipocytes.

Lipid accumulation in adipose tissues occurs at a late stage in adipogenesis. For this reason, Oil Red $\mathrm{O}$ staining was performed following EEc extract treatment in the 3T3-L1 adipocytes. We found that the EEc extract-treated group exhibited a marked decrease in the number of lipid droplets and lipid storage organelles compared to the MDI-treated group (Fig. 3). To confirm that the decrease in lipid accumulation shown in Figs. 2 and 3 was due to downregulation of the differentiation-related transcription factors $\mathrm{C} / \mathrm{EBP} \alpha / \beta / \delta$ and PPAR $\gamma$, we examined their expression levels by Western blot analysis. Differentiation of pre-adipocytes into adipocytes is tightly controlled by the sequential activation of several transcriptional factors, including $\mathrm{C} / \mathrm{EBP} \alpha, \mathrm{C} / \mathrm{EBP} \beta, \mathrm{C} / \mathrm{EBP} \delta$ and PPAR $\gamma(16,17)$. Generally, C/EBP $\beta$ functions rapidly following the induction of pre-adipocyte differentiation, followed by the expression of $\mathrm{C} / \mathrm{EBP} \alpha$ and PPAR $\gamma(18,19)$. As shown in Fig. 4, treatment with EEc extract decreased the expression of $\mathrm{C} / \mathrm{EBP} \alpha$ but did not affect the expression of $\mathrm{C} / \mathrm{EBP} \beta, \mathrm{C} / \mathrm{EBP} \delta$, or PPAR $\gamma$.

Adipogenesis is regulated by a complex transcriptional cascade, in which members of the C/EBP family and PPAR $\gamma$ play important roles in the expression of adipogenesis-related genes, such as SREBP-1c, A-FABP, FAS, GLUT4, LPL and SCD-1, which are involved in insulin sensitivity, lipogenesis and lipolysis (16-20). A role for C/EBP in coordinating transcription during pre-adipocyte differentiation was indicated by its ability to transactivate the promoters of several adipogenesis-specific genes (21-24). The activation of C/EBP $\alpha$ promotes differentiation of pre-adipocytes by cooperating with PPAR $\gamma$, resulting in transactivation of adipogenesis-specific genes such as A-FABP and FAS (26).

SREBP-1 is the first transcription factor involved in adipocyte differentiation, and it increases the expression of several lipogenesis-related genes, including LPL, ACC and FAS (38). To determine the expression of adipogenesis-related genes, SREBP-1c, A-FABP, FAS, GLUT4, adiponectin and leptin were examined by Western blotting. As shown in Fig. 5, EEc extract treatment decreased the expression of SREBP-1c, A-FABP, FAS and adiponectin in a dose-dependent manner compared to levels noted in the MDI-treated group. Our results demonstrated that EEc extract treatment appears to have an inhibitory effect on adipogenesis by reducing the expression of differentiation-related transcription factors and adipogenesis-related proteins in 3T3-L1 adipocytes.

In the present study, most genes examined were early markers of adipogenesis and related transcription factors. Based on the present findings, future research will assess markers at different time points including the early stage of differentiation using pre-adipocytes.

Our results demonstrated that EEc extract treatment inhibited adipogenesis in 3T3-L1 adipocytes, shown by the significant reduction in glucose utilization and TG accumu- lation without cytotoxicity. The suppressive effects of EEc extract treatment may be mediated by downregulation of the expression of adipogenesis-related genes. Therefore, EEc extract treatment may be a potential therapeutic agent for the prevention of obesity.

\section{Acknowledgements}

This study was supported by the Fishery Commercialization Technology Development Program through iPET (Korea Institute of Planning and Evaluation for Technology in Food, Agriculture, Forestry and Fisheries) funded by the Ministry of Oceans and Fisheries (MOF) (no. 111090-03-3-HD110). In addition, this study was supported by the Basic Science Research Program through the National Research Foundation of Korea funded by the Ministry of Education (grant no. 2012R1A6A1028677).

\section{References}

1. Formiguera X and Cantón A: Obesity: Epidemiology and clinical aspects. Best Pract Res Clin Gastroenterol 18: 1125-1146, 2004.

2. Albu J, Allison D, Boozer CN, Heymsfield S, Kissileff H, Kretser A, Krumhar K, Leibel R, Nonas C, Pi-Sunyer X, et al: Obesity solutions: Report of a meeting. Nutr Rev 55: 150-156, 1997.

3. Hossain P, Kawar B and El Nahas M: Obesity and diabetes in the developing world - a growing challenge. N Engl J Med 356: 213-215, 2007.

4. Caro JF, Dohm LG, Pories WJ and Sinha MK: Cellular alterations in liver, skeletal muscle, and adipose tissue responsible for insulin resistance in obesity and type II diabetes. Diabetes Metab Rev 5: 665-689, 1989.

5. Aggoun Y: Obesity, metabolic syndrome, and cardiovascular disease. Pediatr Res 61: 653-659, 2007.

6. Fujioka K: Management of obesity as a chronic disease: Nonpharmacologic, pharmacologic, and surgical options. Obes Res 10 (Suppl 2): 116S-123S, 2002.

7. Després JP and Lemieux I: Abdominal obesity and metabolic syndrome. Nature 444: 881-887, 2006.

8. Rosen ED and Spiegelman BM: Adipocytes as regulators of energy balance and glucose homeostasis. Nature 444: 847-853, 2006.

9. Yang J, Eliasson B, Smith U, Cushman SW and Sherman AS: The size of large adipose cells is a predictor of insulin resistance in first-degree relatives of type 2 diabetic patients. Obesity (Silver Spring) 20: 932-938, 2012.

10. Balkau B, Valensi P, Eschwège E and Slama G: A review of the metabolic syndrome. Diabetes Metab 33: 405-413, 2007.

11. Kopelman PG: Obesity as a medical problem. Nature 404: 635-643, 2000.

12. Abate N: Obesity and cardiovascular disease. Pathogenetic role of the metabolic syndrome and therapeutic implications. J Diabetes Complications 14: 154-174, 2000.

13. Zhang JW, Tang QQ, Vinson C and Lane MD: Dominant-negative $\mathrm{C} / \mathrm{EBP}$ disrupts mitotic clonal expansion and differentiation of 3T3-L1 preadipocytes. Proc Natl Acad Sci USA 101: 43-47, 2004.

14. Kwon JY, Seo SG, Heo YS, Yue S, Cheng JX, Lee KW and Kim KH: Piceatannol, natural polyphenolic stilbene, inhibits adipogenesis via modulation of mitotic clonal expansion and insulin receptor-dependent insulin signaling in early phase of differentiation. J Biol Chem 287: 11566-11578, 2012.

15. Tang QQ, Otto TC and Lane MD: CCAAT/enhancer-binding protein beta is required for mitotic clonal expansion during adipogenesis. Proc Natl Acad Sci USA 100: 850-855, 2003.

16. Christy RJ, Kaestner KH, Geiman DE and Lane MD: CCAAT/enhancer binding protein gene promoter: Binding of nuclear factors during differentiation of 3T3-L1 preadipocytes. Proc Natl Acad Sci USA 88: 2593-2597, 1991.

17. Farmer SR: Regulation of PPARgamma activity during adipogenesis. Int J Obes 29 (Suppl 1): S13-S16, 2005.

18. Farmer SR: Transcriptional control of adipocyte formation. Cell Metab 4: 263-273, 2006. 
19. Lowe CE, $O$ 'Rahilly $S$ and Rochford JJ: Adipogenesis at a glance. J Cell Sci 124: 2681-2686, 2011.

20. Xu A, Wang Y, Xu JY, Stejskal D, Tam S, Zhang J, Wat NM, Wong WK and Lam KS: Adipocyte fatty acid-binding protein is a plasma biomarker closely associated with obesity and metabolic syndrome. Clin Chem 52: 405-413, 2006.

21. Hassan M, El Yazidi C, Landrier JF, Lairon D, Margotat A and Amiot MJ: Phloretin enhances adipocyte differentiation and adiponectin expression in 3T3-L1 cells. Biochem Biophys Res Commun 361: 208-213, 2007.

22. Rosen ED and MacDougald OA: Adipocyte differentiation from the inside out. Nat Rev Mol Cell Biol 7: 885-896, 2006.

23. Nicholson AC, Hajjar DP, Zhou X, He W, Gotto AM Jr and Han J: Anti-adipogenic action of pitavastatin occurs through the coordinate regulation of PPARgamma and Pref- 1 expression. $\mathrm{Br}$ J Pharmacol 151: 807-815, 2007.

24. Yeh WC, Cao Z, Classon M and McKnight SL: Cascade regulation of adipocyte terminal differentiation by three members of the C/EBP family of leucine zipper proteins. Genes Dev 15 : $168-181,1995$.

25. Bray GA and Tartaglia LA: Medicinal strategies in the treatment of obesity. Nature 404: 672-677, 2000.

26. Alemany M, Remesar X and Fernández-López JA: Drug strategies for the treatment of obesity. IDrugs 6: 566-572, 2003.

27. Elangbam CS: Review paper: Current strategies in the development of anti-obesity drugs and their safety concerns. Vet Pathol 46: 10-24, 2009.

28. Rodgers RJ, Tschöp MH and Wilding JP: Anti-obesity drugs: Past, present and future. Dis Model Mech 5: 621-626, 2012

29. Buyukhatipoglu H: A possibly overlooked side effect of Orlistat: Gastroesophageal reflux disease. J Natl Med Assoc 100: 1207, 2008.

30. van der Zwaal EM, Janhunen SK, Luijendijk MC, Baclesanu R, Vanderschuren LJ, Adan RA and La Fleur SE: Olanzapine and sibutramine have opposing effects on the motivation for palatable food. Behav Pharmacol 23: 198-204, 2012.

31. Apfelbaum M, Vague P, Ziegler O, Hanotin C, Thomas F and Leutenegger E: Long-term maintenance of weight loss after a very-low-calorie diet: A randomized blinded trial of the efficacy and tolerability of sibutramine. Am J Med 106: 179-184, 1999.

32. Cunha L and Grenha A: Sulfated seaweed polysaccharides as multifunctional materials in drug delivery applications. Mar Drugs 14: 1-41, 2016.

33. Grasa-López A, Miliar-García Á, Quevedo-Corona L, Paniagua-Castro N, Escalona-Cardoso G, Reyes-Maldonado E and Jaramillo-Flores ME: Undaria pinnatifida and fucoxanthin ameliorate lipogenesis and markers of both inflammation and cardiovascular dysfunction in an animal model of diet-induced obesity. Mar Drugs 14: 148, 2016.

34. Geisen U, Zenthoefer M, Peipp M, Kerber J, Plenge J, Managò A, Fuhrmann M, Geyer R, Hennig S, Adam D, et al: Molecular mechanisms by which a Fucus vesiculosus extract mediates cell cycle inhibition and cell death in pancreatic cancer cells. Mar Drugs 13: 4470-4491, 2015.

35. Gomes DL, Telles CB, Costa MS, Almeida-Lima J, Costa LS Keesen TS and Rocha HA: Methanolic extracts from brown seaweeds Dictyota cilliolata and Dictyota menstrualis induce apoptosis in human cervical adenocarcinoma HeLa cells. Molecules 20: 6573-6591, 2015.

36. Pereira DM, Cheel J, Areche C, San-Martin A, Rovirosa J, Silva LR, Valentao P and Andrade PB: Anti-proliferative activity of meroditerpenoids isolated from the brown alga Stypopodium flabelliforme against several cancer cell lines. Mar Drugs 9: 852-862, 2011.

37. Patra S, Muthuraman MS, Prabhu AR, Priyadharshini RR and Parthiban S: Evaluation of antitumor and antioxidant activity of Sargassum tenerrimum against Ehrlich ascites carcinoma in mice. Asian Pac J Cancer Prev 16: 915-921, 2015.

38. Moussavou G, Kwak DH, Obiang-Obonou BW, Maranguy CA, Dinzouna-Boutamba SD, Lee DH, Pissibanganga OG, Ko K, Seo JI and Choo YK: Anticancer effects of different seaweeds on human colon and breast cancers. Mar Drugs 12: 4898-4911, 2014.

39. Wang FW: Bioactive metabolites from Guignardia sp., an endophytic fungus residing in Undaria pinnatifida. Chin J Nat Med 10: 72-76, 2012.

40. Wang $\mathrm{H}, \mathrm{Fu} \mathrm{Z}$ and Han C: The potential applications of marine bioactives against diabetes and obesity. Am J Mar Sci 2: 1-8, 2014.

41. Wijesinghe WA and Jeon YJ: Exploiting biological activities of brown seaweed Ecklonia cava for potential industrial applications: A review. Int J Food Sci Nutr 63: 225-235, 2012.
42. Athukorala Y, Kim KN and Jeon YJ: Antiproliferative and antioxidant properties of an enzymatic hydrolysate from brown alga, Ecklonia cava. Food Chem Toxicol 44: 1065-1074, 2006.

43. Park MH, Heo SJ, Park PJ, Moon SH, Sung SH, Jeon BT and Lee SH: 6,6'-bieckol isolated from Ecklonia cava protects oxidative stress through inhibiting expression of ROS and proinflammatory enzymes in high-glucose-induced human umbilical vein endothelial cells. Appl Biochem Biotechnol 174: 632-643, 2014.

44. Lee SH, Park MH, Kang SM, Ko SC, Kang MC, Cho S, Park PJ, Jeon BT, Kim SK, Han JS, et al: Dieckol isolated from Ecklonia cava protects against high-glucose induced damage to rat insulinoma cells by reducing oxidative stress and apoptosis. Biosci Biotechnol Biochem 76: 1445-1451, 2012.

45. Kang SM, Lee SH, Heo SJ, Kim KN and Jeon YJ: Evaluation of antioxidant properties of a new compound, pyrogallol-phloroglucinol-6,6'-bieckol isolated from brown algae, Ecklonia cava. Nutr Res Pract 5: 495-502, 2011.

46. Li Y, Qian ZJ, Ryu B, Lee SH, Kim MM and Kim SK: Chemical components and its antioxidant properties in vitro: An edible marine brown alga, Ecklonia cava. Bioorg Med Chem 17: 1963-1973, 2009.

47. Yang YI, Jung SH, Lee KT and Choi JH: 8,8'-Bieckol, isolated from edible brown algae, exerts its anti-inflammatory effects through inhibition of $\mathrm{NF}-\kappa \mathrm{B}$ signaling and ROS production in LPS-stimulated macrophages. Int Immunopharmacol 23: 460-468, 2014

48. Lee SH, Ko CI, Jee Y, Jeong Y, Kim M, Kim JS and Jeon YJ: Anti-inflammatory effect of fucoidan extracted from Ecklonia cava in zebrafish model. Carbohydr Polym 92: 84-89, 2013.

49. Lee SH, Ko CI, Ahn G, You S, Kim JS, Heu MS, Kim J, Jee Y and Jeon YJ: Molecular characteristics and anti-inflammatory activity of the fucoidan extracted from Ecklonia cava. Carbohydr Polym 89: 599-606, 2012

50. Shin HC, Hwang HJ, Kang KJ and Lee BH: An antioxidative and antiinflammatory agent for potential treatment of osteoarthritis from Ecklonia cava. Arch Pharm Res 29: 165-171, 2006.

51. Ahn G, Lee W, Kim KN, Lee JH, Heo SJ, Kang N, Lee SH, Ahn CB and Jeon YJ: A sulfated polysaccharide of Ecklonia cava inhibits the growth of colon cancer cells by inducing apoptosis. EXCLI J 14: 294-306, 2015.

52. Ahn JH, Yang YI, Lee KT and Choi JH: Dieckol, isolated from the edible brown algae Ecklonia cava, induces apoptosis of ovarian cancer cells and inhibits tumor xenograft growth. J Cancer Res Clin Oncol 141: 255-268, 2015.

53. Lee W, Oh JY, Kim EA, Kang N, Kim KN, Ahn G and Jeon YJ: A prebiotic role of Ecklonia cava improves the mortality of Edwardsiella tarda-infected zebrafish models via regulating the growth of lactic acid bacteria and pathogen bacteria. Fish Shellfish Immunol 54: 620-628, 2016.

54. Lee W, Ahn G, Oh JY, Kim SM, Kang N, Kim EA, Kim KN, Jeong JB and Jeon YJ: A prebiotic effect of Ecklonia cava on the growth and mortality of olive flounder infected with pathogenic bacteria. Fish Shellfish Immunol 51: 313-320, 2016.

55. Yang YI, Woo JH, Seo YJ, Lee KT,Lim Y and Choi JH: Protective effect of brown alga phlorotannins against hyper-inflammatory responses in lipopolysaccharide-induced sepsis models. J Agric Food Chem 64: 570-578, 2016.

56. Choi YH: The cytoprotective effects of ethanol extract of Ecklonia cava against oxidative stress are associated with upregulation of Nrf2-mediated HO-1 and NQO-1 expression through activation of the MAPK pathway. Gen Physiol Biophys 35: 45-53, 2016.

57. Shin H, Cho AR, Kim DY, Munkhbayer S, Choi SJ, Jang S, Kim SH, Shin HC and Kwon O: Enhancement of human hair growth using Ecklonia cava polyphenols. Ann Dermatol 28: 15-21, 2016

58. Chang MY, Han SY, Shin HC, Byun JY, Rah YC and Park MK: Protective effect of a purified polyphenolic extract from Ecklonia cava against noise-induced hearing loss: Prevention of temporary threshold shift. Int J Pediatr Otorhinolaryngol 87: 178-184, 2016.

59. Park SJ and Jeon YJ: Dieckol from Ecklonia cava suppresses the migration and invasion of HT1080 cells by inhibiting the focal adhesion kinase pathway downstream of Rac1-ROS signaling. Mol Cells 33: 141-149, 2012.

60. Bae MJ, Karadeniz F, Ahn BN and Kong CS: Evaluation of effective MMP inhibitors from eight different brown algae in human fibrosarcoma HT1080 cells. Prev Nutr Food Sci 20: $153-161,2015$. 
61. Kim EK, Tang Y, Kim YS, Hwang JW, Choi EJ, Lee JH, Lee SH Jeon YJ and Park PJ: First evidence that Ecklonia cava-derived dieckol attenuates MCF-7 human breast carcinoma cell migration. Mar Drugs 13: 1785-1797, 2015.

62. Choi BW, Lee HS, Shin HC and Lee BH: Multifunctional activity of polyphenolic compounds associated with a potential for Alzheimer's disease therapy from Ecklonia cava. Phytother Res 29: 549-553, 2015.

63. Douglas TE, Dokupil A, Reczyńska K, Brackman G, Krok-Borkowicz M, Keppler JK, Božič M, Van Der Voort P, Pietryga K, Samal SK, et al: Enrichment of enzymatically mineralized gellan gum hydrogels with phlorotannin-rich Ecklonia cava extract Seanol ${ }^{\circledR}$ to endow antibacterial properties and promote mineralization. Biomed Mater 11: 045015, 2016.

64. Choi HS, Jeon HJ, Lee OH and Lee BY: Dieckol, a major phlorotannin in Ecklonia cava, suppresses lipid accumulation in the adipocytes of high-fat diet-fed zebrafish and mice: Inhibition of early adipogenesis via cell-cycle arrest and AMPK $\alpha$ activation. Mol Nutr Food Res 59: 1458-1471, 2015.

65. You HN, Lee HA, Park MH, Lee JH and Han JS: Phlorofucofuroeckol A isolated from Ecklonia cava alleviates postprandial hyperglycemia in diabetic mice. Eur J Pharmacol 752: 92-96, 2015

66. Jeon HJ, Choi HS, Lee YJ, Hwang JH, Lee OH, Seo MJ, Kim KJ and Lee BY: Seapolynol extracted from Ecklonia cava inhibits adipocyte differentiation in vitro and decreases fat accumulation in vivo. Molecules 20: 21715-21731, 2015.

67. Park EY, Choi H, Yoon JY, Lee IY, Seo Y, Moon HS, Hwang JH and Jun HS: Polyphenol-rich fraction of Ecklonia cava improves nonalcoholic fatty liver disease in high fat diet-fed mice. Mar Drugs 13: 6866-6883, 2015.

68. Lee SH and Jeon YJ: Efficacy and safety of a dieckol-rich extract (AG-dieckol) of brown algae, Ecklonia cava, in pre-diabetic individuals: A double-blind, randomized, placebo-controlled clinical trial. Food Funct 6: 853-858, 2015.
69. Ko SC, Lee M, Lee JH, Lee SH, Lim Y and Jeon YJ: Dieckol, a phlorotannin isolated from a brown seaweed, Ecklonia cava, inhibits adipogenesis through AMP-activated protein kinase (AMPK) activation in 3T3-L1 preadipocytes. Environ Toxicol Pharmacol 36: 1253-1260, 2013.

70. Kim H, Kong CS, Lee JI, Kim H, Baek S and Seo Y: Evaluation of inhibitory effect of phlorotannins from Ecklonia cava on triglyceride accumulation in adipocyte. J Agric Food Chem 61: 8541-8547, 2013

71. Hong SY, Park JY, Sohn JS, Kim JH and Kim MK: Effects of garcinia cambogia extract feeding on body weight and lipid profiles in rats fed a high-carbohydrate or high-fat diet. Food Sci Biotechnol 18: 649-654, 2009.

72. Chuah LO, Yeap SK, Ho WY, Beh BK and Alitheen NB: In vitro and in vivo toxicity of garcinia or hydroxycitric Acid: A review. Evid Based Complement Alternat Med 2012: 197920, 2012.

73. Krishnamoorthy V, Nagappan P, Sereen AK and Rajendran R: Preliminary phytochemical screening of the fruit rind of Garcinia cambogia and leaves of Bauhinia variegate-A comparative study. Int J Curr Microbiol App Sci 3: 479-486, 2014.

74. Ahn GN, Kim KN, Cha SH, Song CB, Lee JH, Heo MS, Yeo IK, Lee NH, Jee YH, Kim JS, et al: Antioxidant activities of phlorotannins purified from Ecklonia cava on free radical scavenging using ESR and $\mathrm{H}_{2} \mathrm{O}_{2}$-mediated DNA damage. Eur Food Res Technol 226: 71-79, 2007.

75. Ahn MJ, Yoon KD, Min SY, Lee JS, Kim JH, Kim TG, Kim SH, Kim NG, Huh H and Kim J: Inhibition of HIV-1 reverse transcriptase and protease by phlorotannins from the brown alga Ecklonia cava. Biol Pharm Bull 27: 544-547, 2004.

76. Le QT, Li Y, Qian ZJ, Kim MM and Kim SK: Inhibitory effects of polyphenols isolated from marine alga Ecklonia cava on histamine release. Process Biochem 44: 168-176, 2008. 